\title{
Molecular Characterization of Antimicrobial Resistance in Escherichia coli from Rabbit Farms in Tai'an, China
}

\author{
Xiaonan Zhao $\mathbb{D}$, Jie Yang, Zijing Ju, Weishan Chang $\mathbb{D}$, and Shuhong Sun \\ College of Animal Science and Technology, Shandong Agricultural University, Taian 271000, China \\ Correspondence should be addressed to Weishan Chang; changweishan@yeah.net and Shuhong Sun; jqybfkyjs@163.com
}

Received 8 September 2017; Revised 13 December 2017; Accepted 28 January 2018; Published 26 February 2018

Academic Editor: Wen-Jun Li

Copyright (c) 2018 Xiaonan Zhao et al. This is an open access article distributed under the Creative Commons Attribution License, which permits unrestricted use, distribution, and reproduction in any medium, provided the original work is properly cited.

\begin{abstract}
To investigate the prevalence and resistance against antimicrobials of Escherichia coli (E. coli) in Taian, March 2016, a total of 55 E. coli strains were isolated from 60 faecal samples of diarrheic rabbits collected from three rabbit farms in Tai'an. The E. coli isolates were assayed for antimicrobial susceptibility and prevalence of resistance genes and Class I integrons and genotyped using Multilocus Sequence Typing (MLST). All the E. coli isolates were sensitive to ceftazidime, ceftriaxone, imipenem, and amikacin, while $78.2 \%$ of the isolates showed resistance against tetracycline, and $65.5 \%$ were resistant against ampicillin. The most common resistance gene detected was $b l a_{\mathrm{TEM}}$, present in $98.2 \%$ of isolates, followed by bla $a_{\mathrm{CTX}-\mathrm{M}}(94.6 \%)$ and sul2 (58.2\%). Class I integrons were detected in 17 out of the $55(30.9 \%)$ E. coli strains. Seven kinds of gene cassette were detected: $d f r A 17+a a d A 5, d f r A 1+$ catB3 + aacA4, aadA2 + LinF,$d f r A 1+\operatorname{aadA1}$, aadA22, $d f r A 12+\operatorname{orfF}+\operatorname{addA2}$, and aadA16 + dfrA27 + arr-3. All the 55 E. coli strains were identified and classified as 13 sequence types (STs); ST302 (22/55, 40.0\%) was the most prevalent type, followed by ST370 (12/55, 21.8\%). This study showed that E. coli isolated from diarrheic farmed rabbits in the Taian area exhibit sometimes very frequent resistance to antimicrobials important to human medicine, which further highlights the need for reasonable use of antibiotics.
\end{abstract}

\section{Introduction}

Antimicrobials, which play a crucial part in animal and human health care, are commonly used to treat bacterial infections and to prevent further spread of the infections within animal groups $[1,2]$. E. coli are commensal bacteria colonizing the intestinal tract of rabbits and other warmblooded animal species [3]. They may frequently be exposed to selection pressure caused by antimicrobial treatments and may contribute considerably to the emergence of antimicrobial resistant bacteria and the spread of antimicrobial resistance [4]. Furthermore, antimicrobial resistant bacteria can be transferred to the humans through the food chain, thus affecting human health.

There are many kinds of molecular mechanisms underlying antimicrobial resistance in bacteria. The mechanisms mediated by integrons are an example of the most studied ones. Integrons, one kind of genetic element, are able to capture exogenous genes and disseminate them through plasmids or transposons in both interspecific and intraspecific ways [5].
Genotyping methods of bacteria have been important in surveillance and analysis, and they enable determination of sources of outbreaks. MLST is based on DNA sequencing data, which makes it specific, repeatable, comparable, and suitable for detecting the evolution of the strains and genetic analysis of microbial populations $[6,7]$.

Most previous studies were focused on the prevalence of antimicrobial resistance of $E$. coli in the main food animal species such as chicken and pigs, but there is a lack of research on antimicrobial resistance in rabbits. Therefore, in this study, we collected faecal samples from rabbit farms in the Taian area and isolated E. coli strains and then analyzed their drug resistance characteristics and the genotypes, in order to provide information to determine reasonable use of antibiotics.

\section{Materials and Methods}

2.1. Description of Sampling Sites. From February to May 2016, 60 faecal samples (20 samples per farm) were randomly collected from diarrhea rabbits on farms in Ningyang, Xintai, 
and Dongping regions in Tai'an, China. The samples were independently collected from individual animals and the farms were chosen based on their scale (the breeding stock was $>1500$ heads). According to current statistics, there are about 15 relatively large rabbit farms in Tai'an, and each farm presumably produces $>4000$ heads annually. Because the sampling process did not harm the animals, ethical approval was not required for the study.

2.2. Samples and E. coli Isolation. Isolation and identification of E. coli were performed as described previously [8], with some modifications. Briefly, about $0.5 \mathrm{~g}$ faecal samples were added to a tube containing $5 \mathrm{~mL}$ of LB (Luria-Bertani) medium and cultured at $37^{\circ} \mathrm{C}$ for $12 \mathrm{~h}$. The bacteria solution was then streaked onto eosin-methylene blue agar (EMB; Hope, Qingdao, China) plates. After incubation at $37^{\circ} \mathrm{C}$ for $18 \sim 24 \mathrm{~h}$, typical colonies on the plate were streaked on MacConkey's agar (MAC; Hope, Qingdao, China) plates. Positive colonies were chosen for further biochemical identification using the API 20E system (Sysmex bioMérieux, Tokyo, Japan).

2.3. Antimicrobial Susceptibility Testing. Antimicrobial susceptibility was tested by the Minimal Inhibition Concentration (MIC) method. Bacteria were cultured at $37^{\circ} \mathrm{C}$ in the LB broth medium for $6 \mathrm{~h}$. The concentration of $E$. coli was adjusted to $1.5 \times 10^{8}$ colony forming unit $(\mathrm{CFU}) / \mathrm{mL}$ in sterile saline. The susceptibility of the E. coli isolates was tested to 14 commonly used antimicrobial agents, including ciprofloxacin (CIP), chloramphenicol (C), nalidixic acid (NA), amoxicillin/clavulanic acid (AML), tobramycin (TB), ceftazidime (CAZ), ceftriaxone (CRO), gentamicin (GEN), sulfamethoxazole/trimethoprim (SXT), imipenem (IMP), tetracycline (TET), ampicillin (AMP), cefoxitin (FOX), and amikacin (AMK). The results were interpreted based on the Clinical and Laboratory Standards Institute (CLSI) standard guidelines [9]. In this study, the E. coli strain ATCC25922 was used as the quality control strain. E. coli isolates that were resistant to more than three classes of antimicrobials were defined as multidrug-resistant (MDR) isolates.

2.4. Detection of Resistance Genes. The E. coli DNA was extracted using Bacterial Genomic DNA Extraction Kit (Tiangen, Beijing, China) and then the resistance genes associated with beta-lactams $\left(b l a_{\mathrm{TEM}}, b l a_{\mathrm{SHV}}, b l a_{\mathrm{OXA}}, b l a_{\mathrm{PSE}}\right.$, and $b l a_{\mathrm{CTX}-\mathrm{M}}$ ), the quinolone-resistance genes ( $q n r A, q n r B$, $q n r S, a a c(6)-I b-c r$, and $q e p A)$, the aminoglycosides-resistance genes (aac(3)-I, aac(3)-II, $\operatorname{aac}(3)-I I I, \operatorname{aac}(3)-I V$, ant(2), and $a a c(6)-I b)$, the tetracycline-resistance genes (tet $A$ and tet $B$ ), the sulfonamides-resistance genes (sul1, sul2, and sul3), and the chloramphenicol-resistance genes ( $\mathrm{cmlA}$ and flor) were amplified by PCR, using the previously reported [10-12] primers and conditions, and the gene sequences were listed in Table 1. In addition, the PCR procedure was repeated twice for all the isolates, and PCR products were analyzed by $1.5 \%$ agarose gel electrophoresis at $100 \mathrm{~V}$ for $1 \mathrm{~h}$. Photos were taken with a gel imaging system (Tanon-2500, Shanghai, China).

2.5. Detection of Integrons. The universal primers for the amplification of Class I integron gene cassette genes were detected by PCR. The primers of cassette FP and cassette $\mathrm{RP}$ were designed according to reference: $5^{\prime}$-TCATGGCTTGTTATGACTGT- $3^{\prime}$ and $5^{\prime}$-GTAGGGCTTATTATGCACGC- $3^{\prime}$. The amplification consisted of an initial denaturation at $94^{\circ} \mathrm{C}$ for $5 \mathrm{~min}, 30$ cycles of denaturation at $94^{\circ} \mathrm{C}$ for $60 \mathrm{~s}$, annealing at $56^{\circ} \mathrm{C}$ for $55 \mathrm{~s}$, and extension at $68^{\circ} \mathrm{C}$ for $6 \mathrm{~min}$. A final extension for $10 \mathrm{~min}$ at $72^{\circ} \mathrm{C}$ was also applied. PCR products were purified and sequenced for the further analysis [13].

2.6. MLST. According to http://bigsdb.pasteur.fr/ecoli/primers_used.html, 8 pairs of primers for housekeeping genes ( $\operatorname{din} B$, icd $A, p a b B, p o l B, p u t P, \operatorname{trp} A, \operatorname{trpB}$, and uid $A$ ) were designed and then used for PCR. The products of PCR amplification were sequenced by Shanghai Sangon Biotech Co., Ltd. and the results were amended using the Chromas and DNA Star software and then submitted to the Pasteur online database (http://bigsdb.pasteur.fr/perl/bigsdb/bigsdb .pl?db=pubmlst_ecoli_seqdef_public\&page=sequenceQuery) for processing. Then the allele number of each housekeeping gene was obtained and the sequence type (ST type) of each strain was acquired.

\section{Results}

3.1. Isolation of E. coli. A total of 55 E. coli strains were isolated from 60 samples: 18 strains were from Ningyang, 20 strains were from Xintai, and 17 strains were from Dongping (Table 3).

3.2. Antimicrobial Susceptibility Test. From Table 2, all the strains were sensitive to ceftazidime, ceftriaxone, imipenem, and amikacin. The highest resistance rate was shown against tetracycline $(46 / 55,78.2 \%)$ and ampicillin $(36 / 55,65.5 \%)$. The two most common antimicrobial resistance profiles of the isolates were AMP-NA-TET $(n=10,18.1 \%)$ and AMP-TET ( $n=8,14.5 \%)$. In addition, 6 strains were sensitive to all the 14 kinds of antibiotics, while there were 50.9\% (28/55) multidrug-resistant strains (Table 3).

3.3. Detection of Resistance Genes. Two kinds of $\beta$-lactamase genes, $b l a_{\mathrm{TEM}}$ and $b l a_{\mathrm{CTX}-\mathrm{M}}$, were the most frequently detected genes at $98.2 \%$ and $94.5 \%$ respectively, followed by sul2, a kind of sulfa drug-resistant gene, with the detection rate of $58.18 \%$. $5(9.1 \%)$ strains had tetB, a tetracyclineresistance gene. 3 strains (5.5\%) had shown resistance to $q n r S$ and 4 strains (7.5\%) to $a a c(6)-I b-c r$, which were quinoloneresistance genes (Table 3 ).

3.4. Detection of Integrons. Class I integrons were detected in $17 \mathrm{E}$. coli isolates out of 55 strains, as the detection rate was $30.9 \%$. Seven kinds of drug-resistance gene cassette were found in those Class I integrons as follows: $d f r A 17+\operatorname{aadA5}$, $d f r A 1+\operatorname{catB} 3+\operatorname{aacA} 4$, aadA2 + LinF, dfrA1 + aadA1, aadA22, $d f r A 12+\operatorname{orfF}+\operatorname{addA2}$, and aadA16 + dfrA27 + arr-3. The most prevalent gene cassettes were $d f r A 1+c a t B 3+a a c A 4$ and $\operatorname{aad} A 2+\operatorname{LinF}($ Table 3$)$.

3.5. MLST. 13 different kinds of STs were identified among all the 55 strains, including 3 STs (ST302, ST468, and ST370) 
TABle 1: Primers for PCR in this study.

\begin{tabular}{|c|c|c|}
\hline Primer name & Sequence $\left(5^{\prime} \rightarrow 3^{\prime}\right)$ & Reference \\
\hline \multirow{2}{*}{$b l a_{\mathrm{TEM}}$} & F: ATTCTTGAAGACGAAAGGGC & \multirow{2}{*}[10]{} \\
\hline & R: ACGCTCAGTGGAACGAAAAC & \\
\hline \multirow{2}{*}{$b l a_{\mathrm{SHV}}$} & F: CACTCAAGGATGTATTGTG & \multirow{2}{*}[10]{} \\
\hline & R: TTAGCGTTGCCAGTGCTCG & \\
\hline \multirow{2}{*}{$b l a_{\mathrm{OXA}}$} & F: ACACAATACATATCAACTTCGC & \multirow{2}{*}[10]{} \\
\hline & R: AGTGTGTTTAGAATGGTGATC & \\
\hline \multirow{2}{*}{$b l a_{\mathrm{PSE}}$} & F: TTT GGT TCCGCG CTA TCT G & \multirow{2}{*}[10]{} \\
\hline & R: TAC TCC GAG CAC CAA ATC CG & \\
\hline \multirow{2}{*}{$b l a_{\mathrm{CTX}-\mathrm{M}}$} & F: CGCTTTGCGATGTGCAG & \multirow{2}{*}[11]{} \\
\hline & R: ACCGCGATATCGTTGGT & \\
\hline \multirow{2}{*}{$q n r A$} & F: ATTTCTCACGCCAGGATTTG & \multirow{2}{*}[12]{} \\
\hline & R: TGCCAGGCACAGATCTTGAC & \\
\hline \multirow{2}{*}{$q n r B$} & F: CGACCTKAGCGGCACTGAAT & \multirow{2}{*}[12]{} \\
\hline & R: GAGCAACGAYGCCTGGTAGYTG & \\
\hline \multirow{2}{*}{$q n r S$} & F: ATGGAAACCTACAATCATAC & \multirow{2}{*}[12]{} \\
\hline & R: AAAAACACCTCGACTTAAGT & \\
\hline \multirow{2}{*}{$a c c\left(6^{\prime}\right)-I b-c r$} & F: TTGCGATGCTCTATGAGTGGCTA & \multirow{2}{*}{ [12] } \\
\hline & R: CTCGAATGCCTGGCGTGTTT & \\
\hline \multirow{2}{*}{$q e p A$} & F: GCAGGTCCAGCAGCGGGTAG & \multirow{2}{*}[12]{} \\
\hline & R: CTTCCTGCCCGAGTATCGTG & \\
\hline \multirow{2}{*}{$\operatorname{aac}(3)-I$} & F: ACCTACTCCCAACATCAGCC & \multirow{2}{*}[10]{} \\
\hline & R: ATATAGATCTCACTACGCGC & \\
\hline \multirow{2}{*}{$\operatorname{aac}(3)-I I$} & F: ACTGTGATGGGATACGCGTC & \multirow{2}{*}[10]{} \\
\hline & R: CTCCGTCAGCGTTTCAGCTA & \\
\hline $\operatorname{aac}(3)-I I I$ & F: CACAAGAACGTGGTCCGCTA & {$[10]$} \\
\hline (2) (J) & R: AACAGGTAAGCATCCGCATC & {$[10]$} \\
\hline $\operatorname{aac}(3)-I V$ & F: CTTCAGGATGGCAAGTTGGT & {$[10]$} \\
\hline 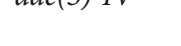 & R: TCATCTCGTTCTCCGCTCAT & \\
\hline $\operatorname{ant}\left(0^{\prime \prime}\right)$ & F: ATGTTACGCAGCAGGGCAGTCG & {$[10]$} \\
\hline & R: CGTCAGATCAATATCATCGTGC & \\
\hline$a c c\left(6^{\prime}\right)-I b$ & F: TTGCGATGCTCTATGAGTGGCTA & {$[10]$} \\
\hline & R: CTCGAATGCCTGGCGTGTTT & \\
\hline tet $A$ & F: GCGCCTTTCCTTTGGGTTCT & {$[10]$} \\
\hline & R: CCACCCGTTCCACGTTGTTA & \\
\hline$t e t B$ & F: CATTAATAGGCGCATCGCTG & {$[10]$} \\
\hline IetB & R: TGAAGGTCATCGATAGCAGG & {$[10]$} \\
\hline sult & F: TGGTGACGGTGTTCGGCATTC & [10] \\
\hline sult & R: GCGAGGGTTTCCGAGAAGGTG & {$[10]$} \\
\hline sul2 & F: CGGCATCGTCAACATAACC & {$[10]$} \\
\hline & R: GTGTGCGGATGAAGTCAG & {$[10]$} \\
\hline sul3 & F: CATTCTAGAAAACAGTCGTAGTTCG & {$[10]$} \\
\hline & R: CATCTGCAGCTAACCTAGGGCTTTGGA & {$[10]$} \\
\hline $\mathrm{cmlA}$ & F: TGTCATTTACGGCATACTCG & [10] \\
\hline & R: ATCAGGCATCCCATTCCCAT & \\
\hline flor & F: CTGAGGGTGTCGTCATCTAC & {$[10]$} \\
\hline & R: GCTCCGACAATGCTGACTAT & \\
\hline
\end{tabular}


TABLE 2: Susceptibility of E. coli to 14 commonly used antibiotics (S: susceptible; I: intermediate; R: resistant).

\begin{tabular}{lccc}
\hline Antibiotics & \multicolumn{2}{c}{ Disk diffusion $[n(\%)]$} & I \\
\hline AML & S & 0 & $2(3.6 \%)$ \\
AMK & $53(96.4 \%)$ & 0 & 0 \\
AMP & $55(100 \%)$ & $4(7.3 \%)$ & $36(65.5 \%)$ \\
C & $15(27.3 \%)$ & $3(5.5 \%)$ & $11(20.0 \%)$ \\
CAZ & $41(74.5 \%)$ & 0 & 0 \\
CIP & 0 & $2(3.6 \%)$ & $10(18.2 \%)$ \\
CRO & $43(78.2 \%)$ & 0 & 0 \\
FOX & 0 & 0 & $1(1.8 \%)$ \\
GEN & $54(98.2 \%)$ & $3(5.5 \%)$ & 0 \\
IMP & $46(83.6 \%)$ & 0 & $3(10.9 \%)$ \\
NA & 0 & $15(27.3 \%)$ & 0 \\
SXT & $10(18.2 \%)$ & $2(3.6 \%)$ & $18(32.7 \%)$ \\
TB & $35(63.6 \%)$ & $8(14.5 \%)$ & $1(1.8 \%)$ \\
TET & $46(83.6 \%)$ & $4(7.3 \%)$ & $43(78.2 \%)$ \\
\hline
\end{tabular}

from samples derived from Ningyang, 6 STs (ST87, ST302, ST314, ST370, ST468, and ST636) from samples derived from Xintai, and 8 STs (ST2, ST24, ST88, ST353, ST370, ST461, ST731, and ST739) from samples derived from Dongping. It was shown that ST302 $(22 / 55,40.0 \%)$ was the most prevalent type, followed by ST370 (12/55, 21.8\%) (Table 3).

\section{Discussion}

Colibacillosis of rabbits, a common disease in rabbits breeding, had become one of the major infectious diseases that endanger the rabbit breeding industry $[14,15]$. In this study, the highest resistance rates of $55 \mathrm{E}$. coli strains were against tetracycline and ampicillin (78.2\% and $65.5 \%$, resp.), higher than those reported from wild rabbits in Portugal, in which the tetracycline and ampicillin resistance rates were both $11.4 \%$ [16]. This coincided with the fact that tetracycline and ampicillin have been widely used to control and prevent rabbit disease in the Taian area. In this study, all the strains were sensitive to ceftazidime, ceftriaxone, imipenem, and amikacin; this may be due to the less frequent use of these antibiotics in rabbit farms. The occurrence of MDR strains is a potential threat to the public health. Our data showed that the proportion of MDR strains among all the E. coli strains was $50.9 \%$, which was lower than that observed from wild rabbits (71.4\%) [16], which may be due to the fact that wild rabbits and hares are commonly found in areas inhabited by human beings and livestock and consequently may share common sources of exposure to antibiotics.

$b l a_{\mathrm{TEM}}$, one kind of $\beta$-lactamase genes, is the most common mechanism of ampicillin resistance in $E$. coli, and it was previously shown in ampicillin-resistant $E$. coli isolates from foods, humans, and healthy animals in Spain [17]. In this study, $98.2 \%$ of $E$. coli isolates carried $b l a_{\mathrm{TEM}}$, whereas only $61.8 \%$ were resistant to ampicillin; this may be associated with the expression status of $b l a_{\text {TEM }}$ genes and is needed to be further studied. Extended-spectrum cephalosporins are critically important antibiotics in human medicine [18], which are also used to treat food-producing animals. The acquirement of extended-spectrum cephalosporins resistance was mainly mediated by extended-spectrum $\beta$-lactamases in E. coli, while the predominant ones were the CTX-M [19]. In this study, $94.5 \%$ of $E$. coli isolates carried $b l a_{\mathrm{CTX}-\mathrm{M}}$, whereas no strains were resistant to cephalosporins; the reason may be that the resistance genes had not yet led to the resistance phenotype. Phenotype could be controlled and verified with the MIC methods. In addition, the quinolone-resistance genes, qnrS (5.5\%) and $a a c(6)-I b-c r(7.5 \%)$, were much less frequent than the report in Sichuan, where aac(6)-Ib-cr (80.4\%) and qnrS (59.8\%) were observed [20]; the difference may be the result of the less frequent use of fluoroquinolone in the Tai'an area, while the detection of the quinoloneresistance genes in this study may come from other sources, such as the contaminated water and food. It has been reported that tet $A$ and $t e t B$ are associated with tetracycline resistance from human and animal sources [21], but our results differed in that tetracycline-resistant $E$. coli in our rabbit were not all carrying tet $A$ or tet $B$; this may be related to regional differences and different breeding conditions. With regard to chloramphenicol-resistant strains, most of them were carrying flor genes; however, $\mathrm{cmlA}$ genes were not very common among chloramphenicol-resistant strains, which was different from other reports, where the flor and $\mathrm{cmlA}$ genes occurred with the same percentage [10]; this difference may be the result of the fact that only partial genes were expressed. The sul1 and/or sul2 and/or sul3 genes were detected in all of the sulfamethoxazole/trimethoprimresistant $E$. coli isolates obtained from rabbits.

In this study, Class I integrons were detected in $17 \mathrm{E}$. coli isolates out of 55 strains (30.91\%), which was similar to the percentage $(31.5 \%)$ of a previous study conducted by Hai et al. [22] but is lower than that of a previous study observed by Dotto et al. (2014) who detected $61.1 \%$ of E. coli strains isolated from domestic and wild Lagomorphs in northern Italy between 2006 and 2008 carrying Class I integrons [23]. Of note, Class I integrons are often associated with MDR 
TABLE 3: Resistance phenotype, ST, incidence of Class I integrons, and resistance gens in E. coli isolated from rabbit farms.

\begin{tabular}{|c|c|c|c|c|}
\hline Numbe & r Location & ST & Resistance phenotype & Integrons/resistance \\
\hline (1) & Ningyang & ST302 & AMP-NA-TET & $b l a_{\mathrm{CTX}-\mathrm{M}}, b l a_{\mathrm{TEM}}$, sul2 \\
\hline (2) & Ningyang & ST302 & AMP-TET & $b l a_{\mathrm{CTX}-\mathrm{M}}, b l a_{\mathrm{TEM}}$, sul2 \\
\hline (3) & Ningyang & ST302 & AMP-NA-TET & Class $1\left(d f r A 17+\right.$ aadA5), bla $a_{\mathrm{CTX}-\mathrm{M}}$, blaTEM, sul2 \\
\hline (4) & Ningyang & ST302 & AMP-TET & $b l a_{\mathrm{CTX}-\mathrm{M}}, b l a_{\mathrm{TEM}}$, sul2 \\
\hline (5) & Ningyang & ST468 & AMP-C-NA-SXT-TET & Class $1\left(d f r A 17+\right.$ aadA5), bla $a_{\mathrm{CTX}-\mathrm{M}}, b l a_{\mathrm{TEM}}$, flor \\
\hline (6) & Ningyang & ST302 & AMP-CIP-NA-SXT-TET & $b l a_{\mathrm{CTX}-\mathrm{M}}, b l a_{\mathrm{TEM}}$, sul2 \\
\hline (7) & Ningyang & ST468 & AMP-C-NA-SXT-TET & Class $1(d f r A 17+a a d A 5), b l a_{\mathrm{CTX}-\mathrm{M}}, b l a_{\mathrm{TEM}}$, sul2 \\
\hline (8) & Ningyang & ST302 & AMP-TET & $b l a_{\mathrm{CTX}-\mathrm{M}}, b l a_{\mathrm{TEM}}$, sul2 \\
\hline (9) & Ningyang & ST302 & AMP-TET & $b l a_{\mathrm{CTX}-\mathrm{M}}, b l a_{\mathrm{TEM}}$, sul2 \\
\hline$(10)$ & Ningyang & ST468 & AMP-CIP-NA-SXT-TET & $b l a_{\mathrm{CTX}-\mathrm{M}}, b l a_{\mathrm{TEM}}$, sul2 \\
\hline (11) & Ningyang & ST302 & AMP-TET & Class 1 (dfrA $1+\operatorname{aadA} 1), b l a_{\mathrm{CTX-M}}, b l a_{\mathrm{TEM}}$, sul 2 \\
\hline (12) & Ningyang & ST370 & & $b l a_{\mathrm{CTX}-\mathrm{M}}, b l a_{\mathrm{TEM}}$ \\
\hline (13) & Ningyang & ST370 & & $b l a_{\mathrm{CTX}-\mathrm{M}}, b l a_{\mathrm{TEM}}$, sull \\
\hline (14) & Ningyang & ST302 & AMP-TET & $b l a_{\text {СTХ-М }}, b l a_{\mathrm{TEM}}$, sull, sul 2 \\
\hline (15) & Ningyang & ST370 & & $b l a_{\mathrm{CTX}-\mathrm{M}}, b l a_{\mathrm{TEM}}$ \\
\hline$(16)$ & Ningyang & ST302 & AMP-NA-TET & $b l a_{\mathrm{CTX}-\mathrm{M}}, b l a_{\mathrm{TEM}}$, sull, sul 2 \\
\hline (17) & Ningyang & ST302 & AMP-TET & $b l a_{\mathrm{CTX}-\mathrm{M}}, b l a_{\mathrm{TEM}}$, sul2 \\
\hline (18) & Ningyang & ST370 & & $b l a_{\mathrm{CTX}-\mathrm{M}}, b l a_{\mathrm{TEM}}$ \\
\hline (19) & Xintai & ST370 & SXT & $b l a_{\mathrm{CTX}-\mathrm{M}}, b l a_{\mathrm{TEM}}$, sull \\
\hline (20) & Xintai & ST87 & GEN-SXT & Class $1\left(d f r A 17+\right.$ aadA5), bla $a_{\mathrm{CTX}-\mathrm{M}}, b l a_{\mathrm{TEM}}, q n r S$, sull \\
\hline (21) & Xintai & ST302 & AMP-GEN-SXT-TET & $b l a_{\mathrm{CTX}-\mathrm{M}}, b l a_{\mathrm{TEM}}$, sul2 \\
\hline (22) & Xintai & ST302 & AMP-NA-TET & $b l a_{\mathrm{CTX}-\mathrm{M}}, b l a_{\mathrm{TEM}}$, sul2 \\
\hline (23) & Xintai & ST370 & & $b l a_{\mathrm{CTX}-\mathrm{M}}, b l a_{\mathrm{TEM}}$ \\
\hline$(24)$ & Xintai & ST302 & & $b l a_{\mathrm{CTX}-\mathrm{M}}, b l a_{\mathrm{TEM}}$, sul1 \\
\hline (25) & Xintai & ST314 & NA-TET & Class $1(d f r A 1+$ catB3 + aacA4 $), b l a_{\mathrm{CTX}-\mathrm{M}}, b l a_{\mathrm{TEM}}$, sul1, sul2 \\
\hline$(26)$ & Xintai & ST302 & AMP-C-NA-SXT-TET & $b l a_{\mathrm{CTX}-\mathrm{M}}, b l a_{\mathrm{TEM}}$, flor, sul 2 \\
\hline$(27)$ & Xintai & ST302 & AMP-FOX-NA-TET & $b l a_{\mathrm{CTX}-\mathrm{M}}, b l a_{\mathrm{TEM}}$, sul2 \\
\hline$(28)$ & Xintai & ST302 & TET & $b l a_{\mathrm{CTX}-\mathrm{M}}, b l a_{\mathrm{TEM}}$, sul 2 \\
\hline$(29)$ & Xintai & ST302 & AMP-NA-SXT & Class $1($ aadA16 $+d f r A 27+a r r-3), a c c\left(6^{\prime}\right)-I b-c r, b l a_{\mathrm{CTX}-\mathrm{M}}, b l a_{\mathrm{TEM}}, s u l 2$ \\
\hline$(30)$ & Xintai & ST636 & & $b l a_{\mathrm{CTX}-\mathrm{M}}, b l a_{\mathrm{TEM}}$, sull \\
\hline$(31)$ & Xintai & ST370 & AMP-NA-TET & $b l a_{\mathrm{CTX}-\mathrm{M}}, b l a_{\mathrm{TEM}}$, sul2 \\
\hline (32) & Xintai & ST468 & AMP-NA-TET & $b l a_{\mathrm{CTX}-\mathrm{M}}, b l a_{\mathrm{TEM}}$, sul2 \\
\hline (33) & Xintai & ST468 & AMP-C-NA-SXT & Class $1(d f r A 1+c a t B 3+a a c A 4), b l a_{\mathrm{CTX}-\mathrm{M}}, b l a_{\mathrm{TEM}}$, flor \\
\hline$(34)$ & Xintai & ST302 & AMP-NA-TET & $b l a_{\mathrm{CTX}-\mathrm{M}}, b l a_{\mathrm{TEM}}$, sul 2 \\
\hline (35) & Xintai & ST302 & AMP-NA-TET & $b l a_{\mathrm{CTX}-\mathrm{M}}, b l a_{\mathrm{TEM}}$, sul 2 \\
\hline$(36)$ & Xintai & ST302 & AMP-NA-TET & $b l a_{\mathrm{CTX}-\mathrm{M}}, b l a_{\mathrm{TEM}}$, sul2 \\
\hline (37) & Xintai & ST302 & AMP -TET & Class $1(d f r A 1+c a t B 3+a a c A 4), b l a_{\mathrm{CTX}-\mathrm{M}}, b l a_{\mathrm{TEM}}$, sul 2 \\
\hline$(38)$ & Xintai & ST370 & NA-TET & Class $1(d f r A 1+\operatorname{catB} 3+a a c A 4), b l a_{\mathrm{CTX}-\mathrm{M}}, b l a_{\mathrm{TEM}}$, sul 1 \\
\hline$(39)$ & Dongping & ST461 & AMP-NA-SXT & $b l a_{\mathrm{TEM}}, q n r S$, sull \\
\hline$(40)$ & Dongping & ST731 & TET & $b l a_{\mathrm{TEM}}$ \\
\hline (41) & Dongping & ST739 & AMP-NA-TET & $a c c\left(6^{\prime}\right)-I b-c r, b l a_{\mathrm{CTX}-\mathrm{M}}, b l a_{\mathrm{TEM}}$ \\
\hline$(42)$ & Dongping & ST370 & TET & $b l a_{\mathrm{CTX}-\mathrm{M}}, b l a_{\mathrm{TEM}}$ \\
\hline$(43)$ & Dongping & ST739 & AMP-CIP- NA-SXT-TET & $a c c\left(6^{\prime}\right)-I b-c r, b l a_{\mathrm{CTX}-\mathrm{M}}, b l a_{\mathrm{TEM}}$ \\
\hline$(44)$ & Dongping & ST370 & TET & $b l a_{\mathrm{CTX}-\mathrm{M}}, b l a_{\mathrm{TEM}}$ \\
\hline$(45)$ & Dongping & ST88 & AML-AMP-C-CIP-GEN- NA-SXT-TET & Class 1 (aadA2 + LinF), bla ${ }_{\mathrm{CTX}-\mathrm{M}}, b l a_{\mathrm{TEM}}, \mathrm{cmlA}$, flor, sul2, sul3, tet $B$ \\
\hline$(46)$ & Dongping & ST370 & TET & $b l a_{\mathrm{CTX}-\mathrm{M}}, b l a_{\mathrm{TEM}}$, sull \\
\hline$(47)$ & Dongping & ST739 & AMP-CIP-NA-SXT-TET & $a c c\left(6^{\prime}\right)-I b-c r, b l a_{\mathrm{CTX}-\mathrm{M}}, b l a_{\mathrm{TEM}}$ \\
\hline$(48)$ & Dongping & ST88 & AMP-C-CIP-GEN-NA-SXT-TET & $b l a_{\mathrm{CTX}-\mathrm{M}}, b l a_{\mathrm{TEM}}$, cmlA, flor, sul2, sul3, tetB \\
\hline$(49)$ & Dongping & ST2 & AMP-C-CIP-NA-SXT-TET & $b l a_{\mathrm{CTX-M}}, b l a_{\mathrm{TEM}}, \mathrm{cmlA}$, flor, sul3 \\
\hline$(50)$ & Dongping & ST88 & AMP-C-CIP-GEN-NA-SXT-TET & Class 1 (aadA2 + LinF), bla ${ }_{\mathrm{CTX}-\mathrm{M}}, b l a_{\mathrm{TEM}}, \mathrm{cmlA}$, flor, sul2, sul3, tet $B$ \\
\hline$(51)$ & Dongping & ST353 & C-TET & Class 1 (aadA22), bla $a_{\mathrm{TEM}}$, flor, qnrS, sul2 \\
\hline$(52)$ & Dongping & ST370 & NA-TET & Class $1\left(d f r A 12+\right.$ orfF + addA2), bla $a_{\mathrm{CTX}-\mathrm{M}}$, sull \\
\hline
\end{tabular}


TABLE 3: Continued.

\begin{tabular}{|c|c|c|c|c|}
\hline Number & Location & ST & Resistance phenotype & Integrons/resistance \\
\hline (53) & Dongping & ST88 & C-CIP-NA-TET & Class $1($ aadA2 + LinF $), b l a_{\text {CTX-M }}, b l a_{\text {TEM }}$, flor, sul2, sul3, tetB \\
\hline$(54)$ & Dongping & ST24 & AML-AMP-TET & Class 1 (aadA22), bla $a_{\mathrm{CTX}-\mathrm{M}}, b l a_{\mathrm{TEM}}$, flor, sul1 \\
\hline (55) & Dongping & ST88 & AMP-C-CIP-GEN-NA-SXT-TB-TET & Class 1 (aadA2 + LinF), bla $a_{\mathrm{CTX}-\mathrm{M}}, b l a_{\mathrm{TEM}}, \mathrm{cmlA}$, flor, sul2, sul 3 , tet $B$ \\
\hline
\end{tabular}

E. coli isolates, consistent with the result of the present study.

In this study, the highest isolation rate of $40 \%$ (22/55) was found for ST302 which had not yet been reported related to infections. It was different from that of previous studies which found that ST40 is the most common ST from rabbits in Italy [23].

\section{Conclusions}

Our findings exhibit the molecular characterization of antimicrobial resistance in Escherichia coli from rabbit farms in Tai'an, China. The rabbits in farms are contaminated with MDR E. coli, which may originate from farms further up the food chain or from horizontal contamination. The high detection rates of MDR E. coli, Class I integrons, and antibioticresistance genes suggested that measures should be taken to reduce the harm to public health, such as the reasonable use of antimicrobials in animal husbandry and culling the reservoirs of pathogens from the slaughter process.

\section{Conflicts of Interest}

The authors declare that they have no conflicts of interest.

\section{Authors' Contributions}

Xiaonan Zhao and Jie Yang have contributed equally to this work.

\section{Acknowledgments}

This work was supported by the National Key R\&D Project of China (2017YFD0500105 and 2016YFD0501608), Taishan Scholars Program (201511023), and Funds of Shandong "Double Tops" Program.

\section{References}

[1] L. Ben Said, A. Jouini, N. Klibi et al., "Detection of extendedspectrum beta-lactamase (ESBL)-producing Enterobacteriaceae in vegetables, soil and water of the farm environment in Tunisia," International Journal of Food Microbiology, vol. 203, pp. 86-92, 2015.

[2] E. A. Reuland, N. Naiemi, S. A. Raadsen et al., "Prevalence of ESBL-producing Enterobacteriaceae in raw vegetables," European Journal Clinical Microbiology \& Infections Diseases, vol. 33, pp. 1843-1846, 2014.

[3] A. E. Van den Bogaard and E. E. Stobberingh, "Epidemiology of resistance to antibiotics: links between animals and humans," International Journal of Antimicrobial Agents, vol. 14, no. 4, pp. 327-335, 2000.
[4] L. Guardabassi, S. Schwarz, and D. H. Lloyd, "Pet animals as reservoirs of antimicrobial-resistant bacteria," Journal of Antimicrobial Chemotherapy, vol. 54, no. 2, pp. 321-332, 2004.

[5] G. D. Wright, "Antibiotic resistance in the environment: a link to the clinic?" Current Opinion in Microbiology, vol. 13, no. 5, pp. 589-594, 2010.

[6] B. Kitchel, J. K. Rasheed, J. B. Patel et al., "Molecular epidemiology of KPC-producing Klebsiella pneumoniae isolates in the United States: clonal expansion of multilocus sequence type 258," Antimicrobial Agents and Chemotherapy, vol. 53, no. 8, pp. 3365-3370, 2009.

[7] A. Salerno, A. Delétoile, M. Lefevre et al., "Recombining population structure of Plesiomonas shigelloides (Enterobacteriaceae) revealed by multilocus sequence typing," Journal of Bacteriology, vol. 189, no. 21, pp. 7808-7818, 2007.

[8] L. Gao, J. Hu, X. Zhang et al., "Application of swine manure on agricultural fields contributes to extended- spectrum Blactamase producing Escherichia coli spread in Taian, China," Frontiers in Microbiology, vol. 6, p. 313, 2015.

[9] CLSI, "Performance standards for antimicrobial susceptibility testing: twentieth-third informational supplement M100-S23," Clinical and Laboratory Standards Institute, Wayne, PA, USA, 2013.

[10] E. V. Navajas-Benito, C. A. Alonso, S. Sanz et al., "Molecular characterization of antibiotic resistance in Escherichia coli strains from a dairy cattle farm and its surroundings," Journal of the Science of Food and Agriculture, vol. 97, no. 1, pp. 362-365, 2017.

[11] C. Valat, K. Forest, M. Billet et al., "Absence of co-localization between pathovar-associated virulence factors and extendedspectrum $\beta$-lactamase (blaCTX-M) genes on a single plasmid," Veterinary Microbiology, vol. 192, pp. 163-166, 2016.

[12] A. A. Moawad, H. Hotzel, A. Omnia et al., "Occurrence of Salmonella enterica and Escherichia coli in raw chicken and beef meat in northern Egypt and dissemination of their antibiotic resistance markers," Gut Pathogens, vol. 9, no. 1, 57 pages, 2017.

[13] P. A. White, C. J. McIver, Y.-M. Deng, and W. D. Rawlinson, "Characterisation of two new gene cassettes, aadA5 and dfrA17," FEMS Microbiology Letters, vol. 182, no. 2, pp. 265-269, 2000.

[14] F. Agnoletti, "Update on rabbit enteric diseases: despit improved diagnostic capacity, where does disease control and prevention stand?" pp. 1113-1127, Proc. 10th World Rabbit Congr, Sharm ElSheikh, Egypt, 2012.

[15] S. Boullier and A. Milon, "Rabbit colibacillosis," in Recent advances in rabbit sciences, ILVO, L. Maertens and P. Coudert, Eds., pp. 171-179, Belgium, Melle, 2006.

[16] N. Silva, G. Igrejas, N. Figueiredo et al., "Molecular characterization of antimicrobial resistance in enterococci and Escherichia coli isolates from European wild rabbit (Oryctolagus cuniculus)," Science of the Total Environment, vol. 408, no. 20, pp. 4871-4876, 2010.

[17] L. Briñas, M. Zarazaga, Y. Sáenz, F. Ruiz-Larrea, and C. Torres, " $\beta$-Lactamases in ampicillin-resistant Escherichia coli isolates 
from foods, humans, and healthy animals," Antimicrobial Agents and Chemotherapy, vol. 46, no. 10, pp. 3156-3163, 2002.

[18] WHO., Critically Important Antimicrobials for Human Medicine, World Health Organization, Geneva, Switzerland, 2011.

[19] U. Naseer and A. Sundsfjord, "The CTX-M conundrum: dissemination of plasmids and Escherichia coli clones," Microbial Drug Resistance, vol. 17, no. 1, pp. 83-97, 2011.

[20] F. K. Qing, G. Yi, H. Y. Ze et al., "Detection of quinolone resistance and plasmid mediated quinolone gene in Escherichia coli isolated from rabbit," Chinese Journal of Preventive Veterinary Medicine, vol. 38, pp. 944-948, 2006.

[21] A. Bryan, N. Shapir, and M. J. Sadowsky, "Frequency and distribution of tetracycline resistance genes in genetically diverse, nonselected, and nonclinical escherichia coli strains isolated from diverse human and animal sources," Applied and Environmental Microbiology, vol. 70, no. 4, pp. 2503-2507, 2004.

[22] S. W. Hai, R. P. Qi, Y. M. Gao et al., "Study on molecular characterization of Class I integron and integron-associated antimicrobial resistance in Escherichia coli from beef cattle," China Animal Husbandry Veterinary Medicine, vol. 41, pp. 63-67, 2014.

[23] G. Dotto, M. Giacomelli, G. Grilli et al., "High prevalence of oqxAB in escherichia coli isolates from domestic and wild lagomorphs in Italy," Microbial Drug Resistance, vol. 20, no. 2, pp. 118-123, 2014. 


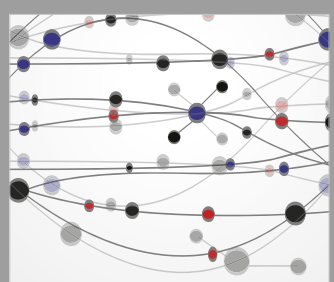

The Scientific World Journal
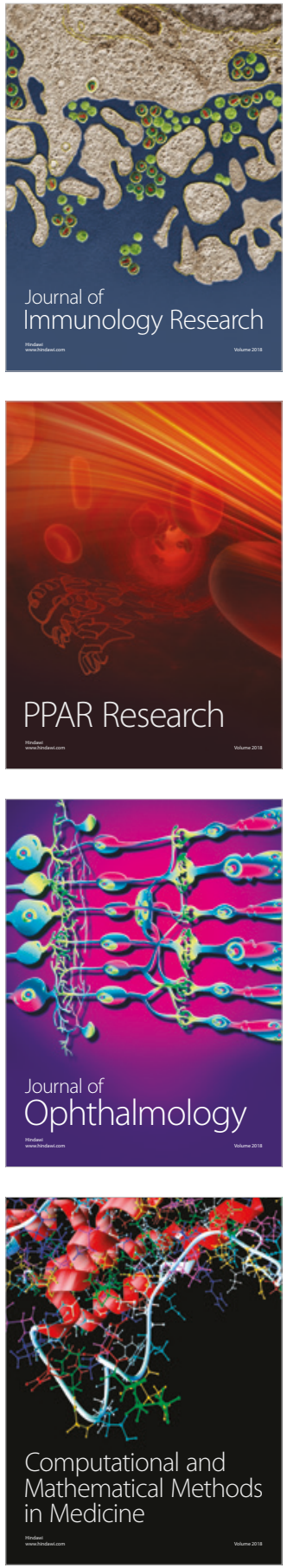

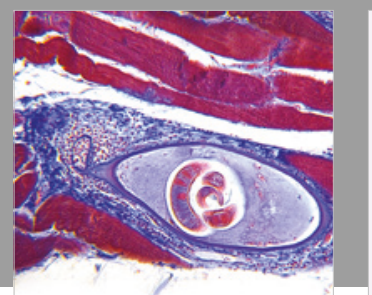

Gastroenterology Research and Practice

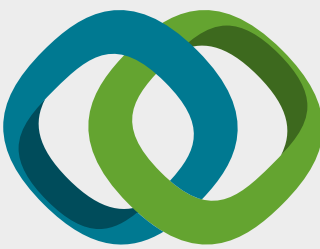

\section{Hindawi}

Submit your manuscripts at

www.hindawi.com
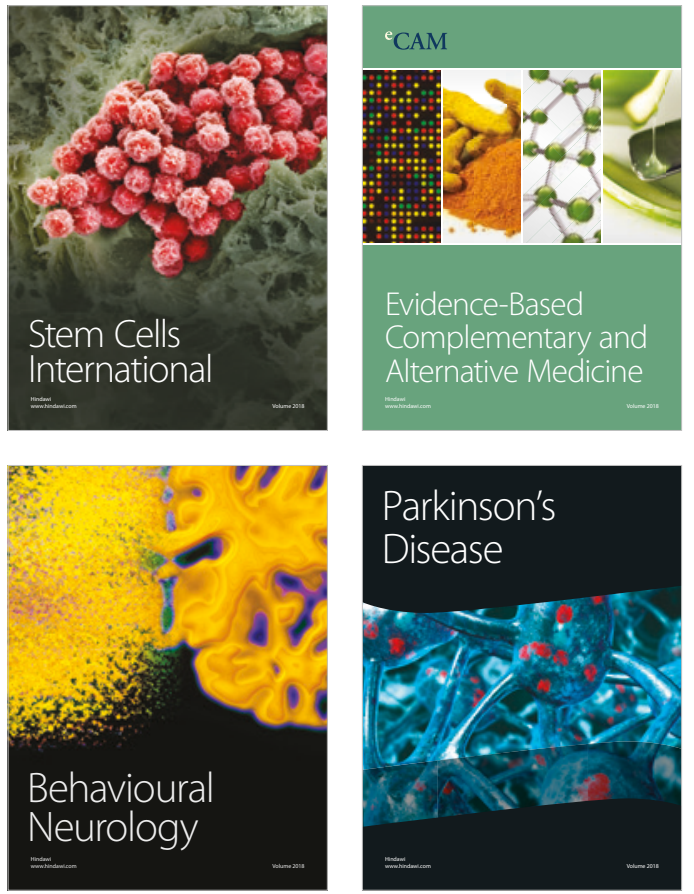

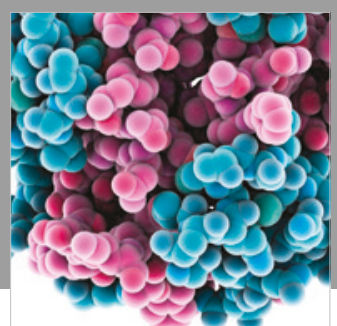

ournal of

Diabetes Research

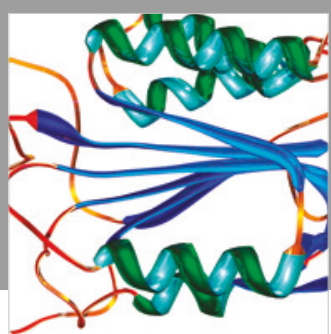

Disease Markers
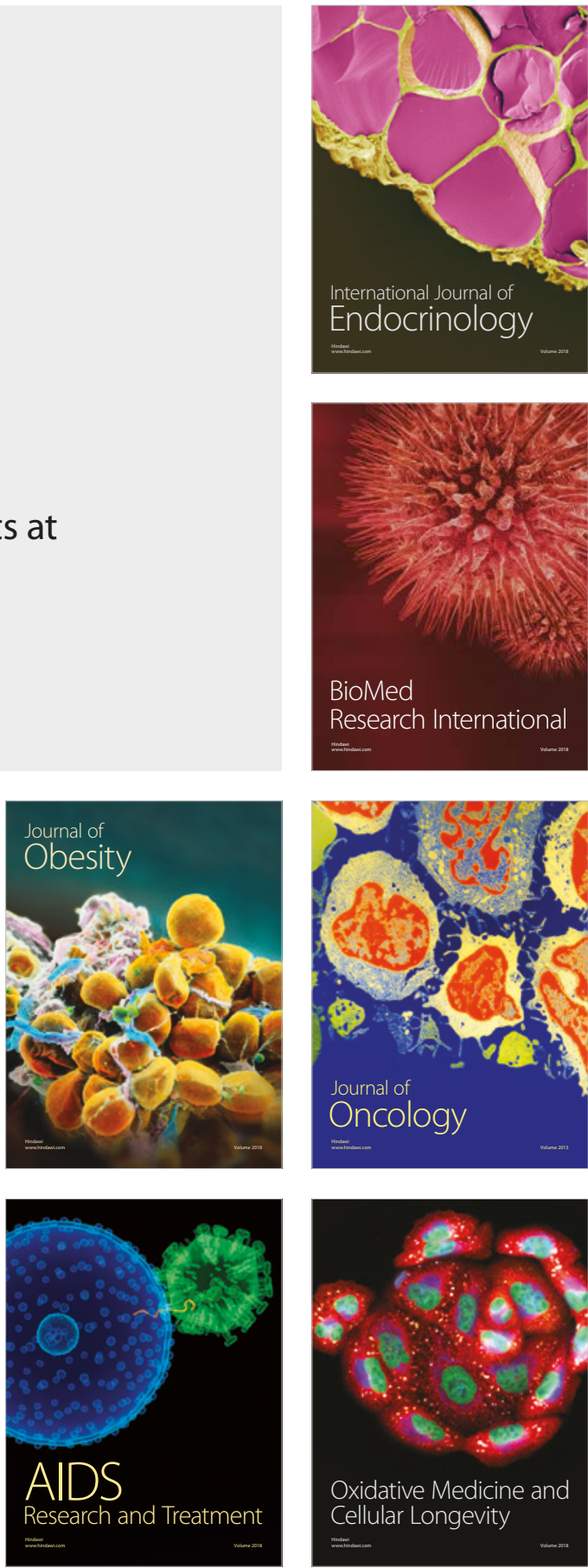